MANTHAN: Journal of Commerce and Management

Volume 4, Issue 2, July-December 2017, pp. 54-64

doi: 10.17492/manthan.v4i02.11461

\title{
Work Engagement in India: Psychometric Evaluation of Utrecht Work Engagement Scale
}

\author{
Urvashi Sharma* and Bhawna Rajput**
}

\begin{abstract}
This paper aims to analyse the psychometric properties of Utrecht Work Engagement Scale (UWES) as developed by Schaufeli et al. (2002) in an India sample. It analyses two models of work engagement i.e. one-factor model, where work engagement is considered as a single construct and three-factor model, which considers three aspects of engagement (vigour, dedication and absorption) of both 17-item UWES and shortened version 9-item UWES. Psychometric properties including factor validity and internal consistency were assessed by an empirical study of 100 employees working in information technology companies in India. The results of confirmatory factor analysis reveal that for India, 9-item UWES and single construct work engagement scale is better than the three factor model. The study further revealed that internal consistency of complete scale was found to be consistent than the three sub-scales for both 9-item UWES and original 17-item UWES. The present study provides an insight as to which measure of UWES works better in context to India.
\end{abstract}

Keywords: Work engagement; Psychometric study; Factorial validity; Reliability; Utrecht Work Engagement Scale (UWES).

\subsection{Introduction}

In $21^{\text {st }}$ century the connection of employees with their work role has gained a lot of prominence. Work engagement is a term that was first coined by Kahn (1990) and since then it has been redefined several times, but no consensus has reached over the definition and the meaning of the term since then. Kahn (1990) has defined work engagement as "expressing of oneself physically, cognitively and emotionally during the work role performance".

*Associate professor, Department of Commerce, Delhi School of Economics, University of Delhi, Delhi, India. (E-mail: urvashi13@gmail.com)

**Corresponding author; Research Scholar, Department of Commerce, Delhi School of Economics, University of Delhi, Delhi, India. (E-mail: bhawnarajput.16@gmail.com) 
One of the most cited and referred definition of the term engagement comes from Schaufeli et al. (2002) which defined engagement as "a positive, fulfilling, work related state of mind that is characterized by vigour, dedication and absorption". Vigour refers to high level of energy and mental resilience while working, whereas dedication refers to being strongly involved in one's work and experiencing a sense of significance, enthusiasm and challenge. Absorption refers to being fully concentrated and happily engrossed in work.

This notion of work engagement is operationalised in Utrecht Work Engagement Scale (UWES) (Schaufeli et al., 2002, 2003), a self-reported questionnaire which captures the three different dimensions of engagement i.e. vigour, dedication and absorption. The original UWES (UWES-17) consists of 17 items Schaufeli et al. (2002): vigour (six items), dedication (five items) and absorption( six items). Shortened version of UWES (UWES-9) with 9 items also got introduced latter by Schaufeli et al., (2006). 9 items UWES also reported to have similar psychometric properties as of UWES-17.Both UEWS-17 and UWES-9 is validated across nations and culture. The main issue with UWES is its factorial validity, initial validation research conducted by authors (Schaufeli et al., 2002, 2003) revealed that the three-factor model of UWES fits the data better than the one-factor model, but one factor-model fits the data in a reasonable manner too.

Several studies supported the three-factor model of UWES over the one-factor model (Littman et al., 2013; Hallberg et al., 2006; Schaufeli et al., 2006; Balducci et al., 2010). However many studies in past have also supported employee engagement as a one-factor model that assumes that all three factors of work engagement load on one underlying dimension, than the three factor model that assumes the three aspects of work engagement (vigour, dedication and absorption) as independent yet correlated. Studies that supported the superiority of one-factor model than three-factor model includes (Shimazu et al., 2008; Vazquez et al., 2015; Klassen et al., 2012; Fong et al., 2015). Many studies have also reported the better fit of UWES-9 as compared to UWES-17 (Nerstad et al., 2010; Simbula and Guglielmi, 2013). The above argument makes it clear that factor structure of UWES does not remain invariant across samples and culture, therefor there is need to test the factor structure of UWES across different cultural group.

UWES has been used widely in the literature of work engagement, however the work on the factorial validity of the scale has mostly come from western countries and very few studies on the same has been reported in India (Pati and Kumar, 2010; Ravichandran et al., 2011; Alok and Israel, 2012; Chaudhary et al., 2011).There is a need to validate the psychometric properties of UWES in Indian context. Therefore, the present study attempts to check the psychometric properties of UWES (both UWES-17 and UWES-9) including structural validity and reliability across as Indian sample. 
Confirmatory factor analysis was used to see whether one-factor or three-factor model fits the data better. Also attempt is made to see whether 9-item UWES or 17-item UWES fits better for Indian sample. In addition to this internal consistency of UWES scale was also assessed.

\subsection{Research Methodology}

\subsection{Participants}

The target population of the present study comprises of employee working at lower, middle and top level in top five Indian Information technology companies i.e. Tata consultancy services, HCL technologies, Infosys, Wipro and Tech Mahindra limited. Data has been collected from total of 100 employees from top five Indian IT companies. Responses were collected through an online survey and send to 130 employees out of which 100 fully completed questionnaire has been received i.e. the response rate was $77 \%$. Demographic Characteristics of the respondents with respect to gender, age and years of experience is shown in Table 1.

Table 1: Demographic Characteristics.

\begin{tabular}{|c|c|c|}
\hline Gender & Frequency & Percentage \\
\hline Male & 67 & $67 \%$ \\
\hline Female & 33 & $33 \%$ \\
\hline Age & Frequency & Percentage \\
\hline $20-30$ & 58 & $58 \%$ \\
\hline $31-40$ & 40 & $40 \%$ \\
\hline $41-50$ & 2 & $2 \%$ \\
\hline Years of experience & Frequency & Percentage \\
\hline $0-3$ & 26 & $26 \%$ \\
\hline $3-6$ & 42 & $42 \%$ \\
\hline $6-9$ & 25 & $25 \%$ \\
\hline 9 and above & 7 & $7 \%$ \\
\hline
\end{tabular}

\subsection{Measures}

Work engagement was measured with 17-item UWES and 9-item UWES as developed by Schaufeli at al. (2000).All items of both the scale was rated on 7 point frequency based scale ( $1=$ Almost never, and $5=$ Always). The items were grouped into three sub scales i.e. vigour, dedication and absorption. In 17-item UWES, vigour was measured with six items (for example, 'at my work, I feel bursting with energy'). 
'Dedication 'was assessed with five items (for example, 'At my job, I feel strong and vigourous') and 'absorption' was measured with six items (for example, 'I am enthusiastic about my job'). In 9-item UWES vigour was assessed with 3 items (for example, 'at my work, I feel bursting with energy'), 'dedication' was measured with 3 items (for example, 'I am enthusiastic about my job') and 'adsorption' was assessed with 3 items (for example, 'I am immersed in my work').

\subsection{Data analysis}

Data were analysed with the help of SPSS 20 and AMOS 24 statistical packages. To test the factorial validity of 17-item UWES and 9-item short version of UWES and to compare the alternative models confirmatory factor analysis were used. Maximum likelihood estimation method was used for the purpose. To test the goodness of fit for each model both absolute and relative indices were utilized. Absolute goodness of fit model was assessed by using $\chi 2$ goodness of fit statistics, the root mean square error of approximation (RMSEA). However $\chi 2$ goodness of fit index does not give good results when applied in isolation as it is quite responsive to sample size. For this purpose the use of relative goodness of fit indices should be used. Relative goodness of fit indices used in the study were the normed fit index (NIF) and comparative fit index (CFI) value greater than 0.09 indicate a good model fit.

\subsection{Results}

The factorial validity of two models i.e. the one factor model(where work engagement is considered as a single construct) and three-factor model (where three subscales of work engagement i.e. vigour, dedication, and absorption were considered) were examined for both 17-item UWES and 9-item UWES. The model fit for both one factor and three factor models for both long and short version of UWES is reported in Table 2 and Table 3 respectively.

Table 2: Result of Confirmatory Factor Analysis for 17-item UWES

\begin{tabular}{|l|c|c|c|c|c|c|c|r|}
\hline \multicolumn{1}{|c|}{ Model } & $\chi \mathbf{2}$ & $\mathbf{d f}$ & $\boldsymbol{\chi} \mathbf{2} / \mathbf{d f}$ & GFI & NFI & TLI & CFI & RMSEA \\
\hline $\begin{array}{l}\mathbf{1 7} \text {-item(3 } \\
\text { factor model) }\end{array}$ & 160.733 & 116 & 1.386 & 0.837 & 0.531 & 0.747 & 0.784 & 0.062 \\
\hline $\begin{array}{l}\mathbf{1 7} \text {-item(1 } \\
\text { factor model) }\end{array}$ & 164.214 & 119 & 1.380 & 0.835 & 0.521 & 0.750 & 0.782 & 0.062 \\
\hline
\end{tabular}


58 | MANTHAN: Journal of Commerce and Management, Volume 4, Issue 2, Jul-Dec 2017

Table 3: Result of Confirmatory Factor Analysis for 9-item UWES

\begin{tabular}{|l|c|c|c|c|c|c|c|c|}
\hline \multicolumn{1}{|c|}{ Model } & $\boldsymbol{\chi 2}$ & $\mathbf{d f}$ & $\boldsymbol{\chi} \mathbf{2} / \mathbf{d f}$ & GFI & NFI & TLI & CFI & RMSEA \\
\hline $\begin{array}{l}\text { 9-item (3 factor } \\
\text { model) }\end{array}$ & 33.986 & 24 & 1.416 & 0.936 & 0.738 & 0.840 & 0.893 & 0.065 \\
\hline $\begin{array}{l}\text { 9-item (1 factor } \\
\text { model) }\end{array}$ & 35.482 & 27 & 1.314 & 0.932 & 0.726 & 0.879 & 0.909 & 0.056 \\
\hline
\end{tabular}

For the three factors and one factor model in case of 17-item UWES, chi square value was statistically significant with $p$ value equals to 0.004 in both cases. Statistically significant $\mathrm{p}$ value shows that the model fit for both three factors and one factor model in case of 17-item UWES is not good. Therefore, relative indices are to be checked to assess the goodness of fit. CFI value for 17-item UWES (One-factor= 0.521 and threefactor $=0.784$ ) which is lower than the CFI guideline of 0.95 .

Figure 1: Three Factor Model of 17-item of UWES

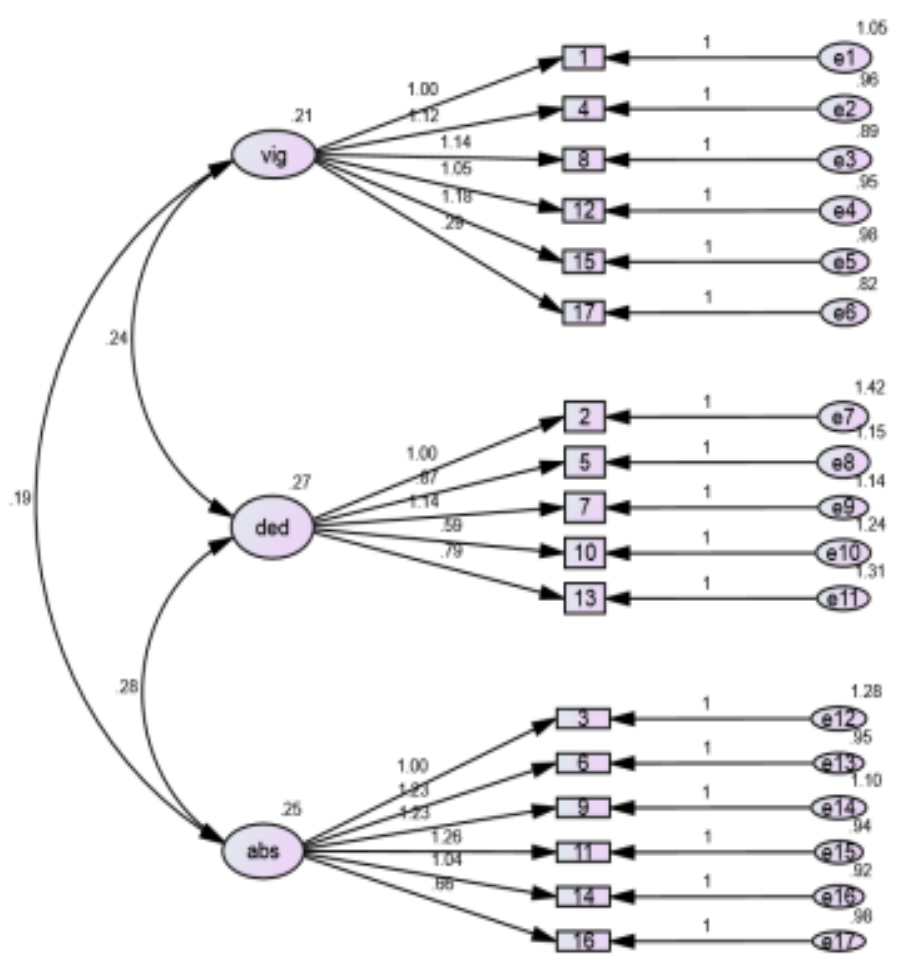


TLI value for 17-item UWES (one-factor= 0.750 and three-factor= 0.747 ) which is again lower than the satisfactory value of 0.90. RMSEA value of 17-item UWES (onefactor $=0.06$ and three-factor $=0.062$ ), any value of lower than 0.8 is acceptable in case of RMSEA. Based on the fit indices of one- factor and three-factor model in case of 17item UWES, model fit is not good but only acceptable (Figures 1 and 2). Comparing the fit indices of one-factor and three-factor of 17-item of UWES, superiority of one- factor model is suggested in context of India. In order to correct the model fit modification indices has not been used as it is not an acceptable practice and no definite conclusion and generalization can be drawn.

Figure 2: One Factor model of 17-item UWES

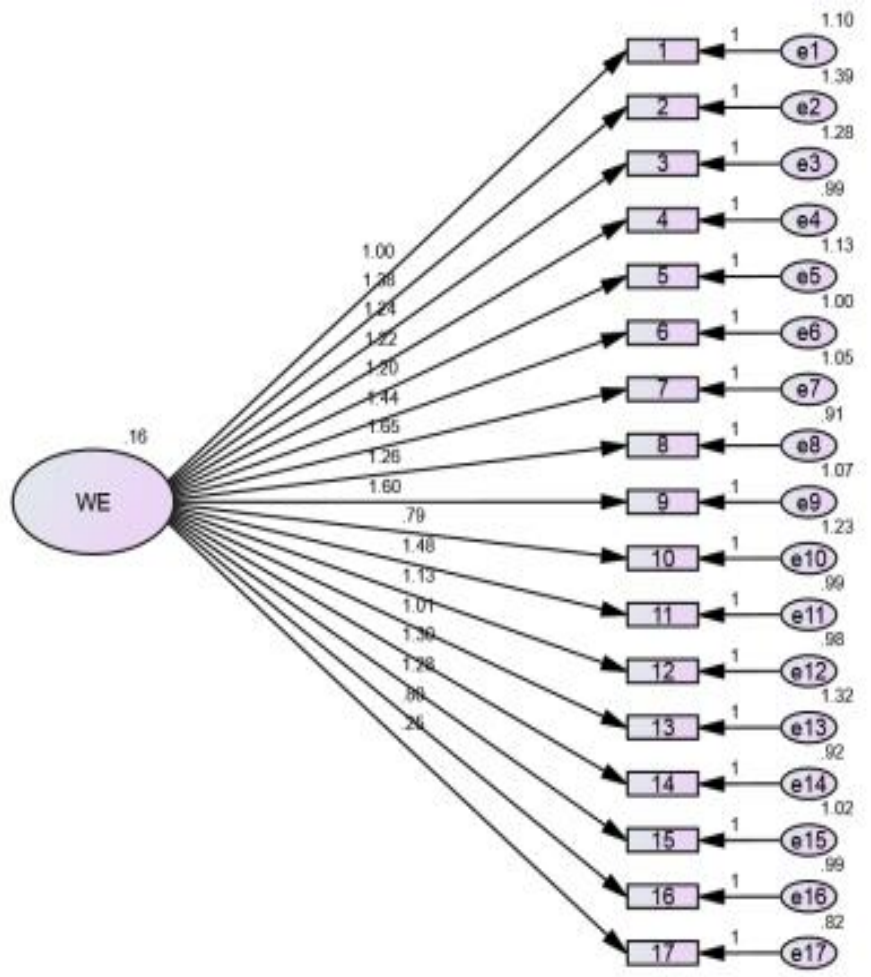

For 9-item UWES the $\mathrm{p}$ value for both one-factor and three-factor is not significant i.e. $p$ value is greater than 0.05 as reported in Table 3 . Non-significant $p$ value shows a good model fit. Apart from absolute indices, relative indices also show a reasonable model fit (Figures 3 and 4 ). 
60 | MANTHAN: Journal of Commerce and Management, Volume 4, Issue 2, Jul-Dec 2017

Figure 3: Three-factor Model of nine-item UWES

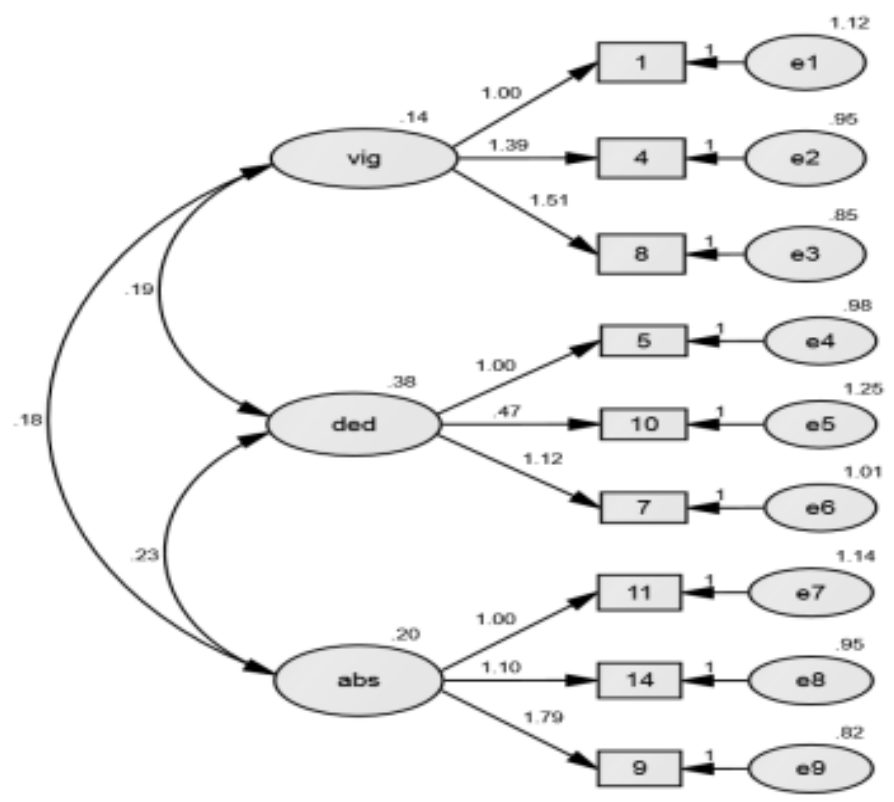

Figure 4: One-factor Model of nine-item UWES

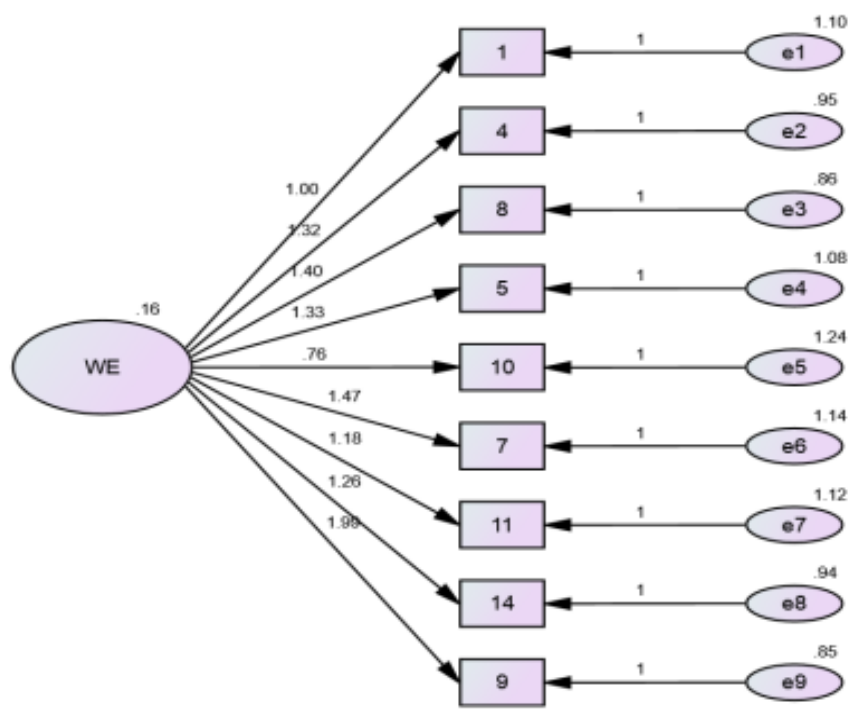


For one-factor model $(\mathrm{CFI}=0.909, \mathrm{TLI}=0.879$ and $\mathrm{RMSEA}=0.056)$ and for three-factor model $(\mathrm{CFI}=0.893$, TLI $=.0840$ and RMSEA $=0.065)$.Fit indices shows that both one-factor and three-factor model of 9-item UWES fit the model reasonably, but comparing the two model indices one -factor model with work engagement as a single construct fit the model better. On comparing the 9-item UWES and 17-item original UWES (Table 2 and 3), the three factor model of 9-item UWES was found to best fit the data.

\subsection{Internal consistency}

Reliability of the data has been calculated using SPSS 20, for that purpose Cronbach's alpha has been used. Cronbach's alpha of 17-item UWES found to be 0.774 which is greater than the minimum recommended value of 0.07 . The internal consistency of subscale of work engagement was found to be 0.559, 0.420, and 0.629 for vigour, dedication and absorption respectively. Reliability of subscales of 17-item UWES found to be much below the acceptable limit of 0.07 .

For 9-item shorten version of UWES, Cronbach's alpha was found to be 0.698 which is almost equal to acceptable limit of 0.07 . Internal consistency of sub scale of 9 item UWES was found to be $0.412,0.386$, and 0.497 for vigour, dedication and absorption respectively. For both versions i.e. long and short version of UWES reliability of complete scale was found to be greater than the subscales. Total scale found to be consistent but subscales were not found to be consistent, this raises the question on the multi dimensionality of UWES across different nations.

\subsection{Discussion and Conclusion}

As seen in literature review, very few studies have been done to examine the psychometric properties of UWES, a scale which is widely used to measure the engagement level of employees. The objective of the present study was to find out the internal consistency and construct validity of both 17-item UWES and short 9-item UWES. Confirmatory factor analysis revealed that 1 factor model shows a better fit than a three-factor model for both 17-item UWES and 9-item UWES. The result is in contravention with the result of previous studies that suggested the better fir of threefactor model over the one-factor model (Schaufeli et al., 2006; Schaufeli et al., 2003; Zecca et al., 2015; Nerstad et al., 2010). In addition to this the fit of one-factor model of 9-item UWES was found to be better than 17-item UWES, this result was consistent with some studies such as Simbula et al., 2013). Further the internal consistency of both 17 item UWES (0.774) and 9-item UWES (0.698) was found to be acceptable and near to 
62 | MANTHAN: Journal of Commerce and Management, Volume 4, Issue 2, Jul-Dec 2017

acceptable value of 0.07 . Surprisingly the reliability of the subscales of both the models was found to be lower and inconsistent. It may be because of the lower sample size used and due to cultural differences.

To conclude the study shows that one-factor model is more appropriate for India as compared to three-factor model, the result of the study was found to be consistent with the previous studies (Shimazu et al., 2008; De Bruin et al., 2013; Fong et al., 2015; Vazquez et al., 2015 ).However the result may not be definitive because the sample for the study was collected at one point of time and from a single group, large scale multigroup sample and multi-point sample shall enhance the confidence in the results. Further exploratory factor analysis can be done to examine the factors of the sub scales of the UWES. Till further studies it is appropriate to consider work engagement as a single factor for India.

\section{References}

Alok, K., \& Israel, D. (2012). Authentic leadership \& work engagement. Indian Journal of Industrial Relations, 47(3), 498-510.

Balducci, C., Fraccaroli, F., \& Schaufeli, W. B. (2010). Psychometric properties of the Italian version of the Utrecht Work Engagement Scale (UWES-9). European Journal of Psychological Assessment, 26(2), 143-149.

Chaudhary, R., Rangnekar, S., \&Barua, M. (2011). Relation between human resource development climate and employee engagement: Results from India. Europe's Journal of Psychology, 7(4), 664-685.

De Bruin, G. P., Hill, C., Henn, C. M., \& Muller, K. P. (2013). Dimensionality of the UWES-17: An item response modelling analysis. SA Journal of Industrial Psychology, 39(2), 1-8.

Fong, T. C., \& Ho, R. T. (2015). Dimensionality of the 9-item Utrecht Work Engagement Scale revisited: A Bayesian structural equation modeling approach. Journal of Occupational Health, 57(4), 353-358.

Hallberg, U. E., \& Schaufeli, W. B. (2006). "Same same" but different? Can work engagement be discriminated from job involvement and organizational commitment?. European psychologist, 11(2), 119-127. 
Kahn, W. A. (1990). Psychological conditions of personal engagement and disengagement at work. Academy of Management Journal, 33(4), 692-724.

Klassen, R. M., Aldhafri, S., Mansfield, C. F., Purwanto, E., Siu, A. F., Wong, M. W., \& Woods-McConney, A. (2012). Teachers' engagement at work: An international validation study. The Journal of Experimental Education, 80(4), 317-337.

Littman-Ovadia, H., \& Balducci, C. (2013). Psychometric properties of the Hebrew version of the Utrecht Work Engagement Scale (UWES-9). European Journal of Psychological Assessment, 29(1), 58-63.

Nerstad, C. G., Richardsen, A. M., \& Martinussen, M. (2010). Factorial validity of the Utrecht Work Engagement Scale (UWES) across occupational groups in Norway. Scandinavian Journal of Psychology, 51(4), 326-333.

Pati, S. P., \& Kumar, P. (2010). Employee engagement: Role of self-efficacy, organizational support \& supervisor support. Indian Journal of Industrial Relations, 46(1), 126-137.

Ravichandran, K., Arasu, R., \& Kumar, S. A. (2011). The impact of emotional intelligence on employee work engagement behavior: An empirical study. International Journal of Business and Management, 6(11), 157-169.

Schaufeli, W. B., \& Bakker, A. B. (2003). UWES-Utrecht work engagement scale: Test manual. Unpublished Manuscript: Department of Psychology, Utrecht University, 8.

Schaufeli, W. B., Bakker, A. B., \& Salanova, M. (2006). The measurement of work engagement with a short questionnaire: A cross-national study. Educational and Psychological Measurement, 66(4), 701-716.

Schaufeli, W. B., Salanova, M., González-Romá, V., \& Bakker, A. B. (2002). The measurement of engagement and burnout: A two sample confirmatory factor analytic approach. Journal of Happiness Studies, 3(1), 71-92.

Shimazu, A., Schaufeli, W. B., Kosugi, S., Suzuki, A., Nashiwa, H., Kato, A., \& Goto, R. (2008). Work engagement in Japan: validation of the Japanese version of the Utrecht Work Engagement Scale. Applied Psychology, 57(3), 510-523. 
64 | MANTHAN: Journal of Commerce and Management, Volume 4, Issue 2, Jul-Dec 2017

Simbula, S., \& Guglielmi, D. (2013). I am engaged, I feel good, and I go the extra-mile: Reciprocal relationships between work engagement and consequences. Revista de Psicología del Trabajo y de lasOrganizaciones, 29(3), 117-125.

Vazquez, A. C. S., Magnan, E. D. S., Pacico, J. C., Hutz, C. S., \& Schaufeli, W. B. (2015). Adaptation and validation of the Brazilian version of the Utrecht work engagement scale. Psico-USF, 20(2), 207-217.

Zecca, G., Györkös, C., Becker, J., Massoudi, K., De Bruin, G. P., \& Rossier, J. (2015). Validation of the French Utrecht Work Engagement Scale and its relationship with personality traits and impulsivity. European Review of Applied Psychology, 65(1), 1928. 